\title{
THE PROPER BASIS OF BOND ACCOUNTS WHEN HELD FOR INVESTMENT
}

\author{
By Charles E. Sprague, Ph.D., New York,
}

President, Union Dime Savings Institution, and Author of "The Accountancy of Investment."

A bond is a complex promise to pay,

I. A certain sum of money at a future time; this is known as the principal, or par.

2. Certain smaller sums, proportionate to the principal, and at various earlier times, these are usually known as the interest, but as they do not necessarily correspond to the true rate of interest, it will be better to speak of them as the coupons.

The sale of a bond is the transfer of the right to receive these various sums at the stipulated times. They are never worth their face, or par, until these times arrive, but are always at discount. The principal is never worth its face until its maturity; the coupons are never worth their face until their maturities. Yet while both principal and coupons are always at a discount, the aggregate may easily be worth more than the principal alone; and it is the aggregate, principal and coupons, which is the subject of the bargain.

The purchaser, in fixing the price which he is willing to pay, is guided by several considerations:

I. The amount of the principal.

2. The amount of each coupon.

3. The length of time to which the principal is deferred.

4. The number of coupons.

5. The times of their payments.

6. The rate of interest which can be earned upon securities of a similar grade.

He discounts the principal and each coupon at compound interest at such rate and for the times which they respectivly ${ }^{1}$ have to run and the sum of these partial present-worths is the value of the bond: If he can buy at a price below this value he will receive a

'The abbreviated spelling is followed in this paper at the special request of the author.-THE EDITor. 
higher rate of interest than he anticipated; if he is required to pay more than this price, he refuses to buy.

As he cashes each coupon, he receives what he paid for it plus interest at the uniform rate; thenceforward he earns interest on a diminisht investment so far as coupons are concerned, but on an increast investment as to principal. If each coupon is less than the total earning during its period there is an increase in the total investment; if it is greater, there is a surplus which operates to reduce the investment or to amortize the premium.

We have then two fixt points in the history of the bond: the original cost or money invested, and the principal sum or par, or money to be received at maturity. Between these two points there is a gradual change; if bought below par, the bond must rise to par ; if above, it must sink to par; these changes being the effect of interest earned and coupons paid. At any intermediate moment there is an investment-value which can be calculated, and which is just as true as the original cost and the par. In fact these latter are merely cases of investment-value; the investment-value at the date of purchase is cost; the investment-value at the date of maturity is par.

The gradual change in the investment is ignored by some investors, who either use the original cost all thru, or the par. In the former case they suppose that the investment value remains at its original figure until the very day of maturity and is instantly reduced to par, by a loss of all the premium or a sudden gain of the discount. Those who use par as the investment-value assume also that there is this sudden change of value but that it took place at the instant of purchase.

These treatments are manifestly fictitious and unreal and only resorted to because the labor of computing intermediate values is shunned. Experience would tell us, if theory did not, that there is no such violent change. In any complete system of bookkeeping (popularly called double entry) the accounts representing assets and those representing profits and losses are mutually dependent. You cannot arbitrarily change a value without affecting and distorting the general profit-and-loss account. A year's actual gain might be swept away, on paper, by the investment, perhaps a very advantageous one, in a security at a premium.

The disappearance of premium being regarded as a consump(194) 
tion of capital, instead of a return requiring reinvestment, the entire coupon is looked upon as income and the impairment of capital becomes actual. In case of a sale, the true profit or loss is unknown, the proceeds being compared either with a value which has past into history or one which is yet to be realized-not with a value which is adjusted to the present. The error in these faulty methods of accountancy arises from the assumption that interest is only earned when specifically collected in cash-that the coupon is exactly the measure of the interest earned.

When the bond is at par this is true: the coupon and the interest are co-extensiv. But if there is any premium or discount we must disregard the distinction between principal and interest and consider that the original investment goes on increasing at compound interest, period by period, but diminisht by the coupons and the final redemption. In other words, we must think of the coupons and the principal as merely instalments, the periodic instalments and the final one, but all of the same nature.

A familiar instance of interest earnings not represented by specific cash payment but by accretion is the discount of a note. If a three-months' note for $\$ \mathrm{I}, 000$ is discounted at 6 per cent, the investment is $\$ 985$, which by accretion becomes $\$ 1,000$. Altho interest is not mentioned, the purchaser earns $\$ 15$, or more than 6 per cent, on his investment of $\$ 985$. If the note were payable three years from now instead of three months, he would expect to earn compound interest and would pay, perhaps, $\$ 837.48$. His earnings on this investment, compounded semi-annually, would bring the investment up to $\$ \mathrm{I}, 000$ in three years. This note would be equivalent to a bond without coupons; no interest is stipulated for, but interest is actually earned. If coupons were added, the bond would simply be worth so much more, according to their value.

I therefore regard the cost and the par value, while correct at the beginning and at the end of the period of ownership, as entirely incorrect during the interim. The true standard is the present worth, compound-discounted, of all recipiends, or sums of cash to be received whether called coupons or principal.

These three values resemble three tenses in grammar: the cost is the past, what was paid; the par is future, what will be received; the investment value is the present. There is a fourth value, which may be considered as in the potential mood; what might be obtained 
on sale, at the present time. This is the market value and is a matter of judgment, opinion and inference. Some bonds are bought and sold so frequently that there is a current quotation which is fairly reliable; other issues, in which dealings are rarer, are valued by analogy with those whose conditions are nearest like them.

It may be observed here that the market value depends solely on the rate of interest which prevails on the particular grade of security. This has sometimes been doubted; even the courts have sometimes assumed that there could be a depreciation, regardless of interest-rate, for the "badness" of the investment; or a premium paid, regardless of interest-rate, for the "excellence" of the security. It is necessary to analyze this view which I regard as essentially unsound.

No one buys a bond by reason of admiration, as he would buy a painting or a statue. He is dealing solely in earnings, that is to say, in interest. $\mathrm{He}$ is impelled by no other motiv than that of receiving his money back with the increment which shall accrue in the meantime. If an investment is offered him which is superlativly "good," but which returns only what he originally invested without any increment, he will certainly refuse it.

The rate of interest, however, is affected by the risk of loss. Every rate of interest may be regarded as composed of two parts: one, a compensation for the use of the capital ; the other, a premium of insurance against chances of loss. Thus an interest-rate of 5 per cent per annum may be conceived as

$3 \%$ riskless interest or compensation for use of capital ;

$+2 \%$ premium for insurance against loss.

Another and safer investment, where the chance of loss is twice as remote, would rate at 4 per cent :

$3 \%$ riskless interest;

$+1 \%$ premium of insurance.

The chance of loss may be very remote, it may be imaginary, but it is worth insuring against. Similarly, the chance of any one house being destroyed by fire is remote, but men willingly pay a part of the income of the house to secure themselves against it. The loss feared in the case of investment is not merely direct loss, or failure to return, but losses by delay, by difficulty of collection, by expense of litigation, by the very feeling of suspense which acts as a penalty. An opinion that the loss is possible is exactly as 
potent as the reality, in producing a loading of the rate on account of risk-insurance, provided this opinion is sufficiently widespread.

A lowering of the grade of security means an increase of the insurance-premium and hence of the rate of interest. This may happen by deterioration of the physical property which underlies the investment, by bad management, by accidental loss of custom and in various ways, preventable or non-preventable.

The other element in the interest-rate, the value of the use of capital, also fluctuates, as in times of capital famin or capital glut, in new countries as against old countries, and it is difficult to decide how much of the rate is due to this source and how much to insurance. But taking the rate as a whole; the question is, does the price of a bond ever vary except thru the interest-rate?

We may test this by experiment. Taking some railroad company which has fallen into misfortune and whose $3^{1 / 2}$ per cent bonds, once at a premium, are now below par, so that their present market price is equivalent to discounting all the recipiends at 4.50. If this depreciation is not entirely a consequence of this high rate of discount, if there is an intrinsic depreciation, it must apply to all obligations of the road. But if the same road now puts out bonds bearing 5 per cent interest under the same mortgage it will invariably be found that these will sell at a premium, on approximately the same $\left(4^{T / 2}\right)$ basis.

We may deduce the following conclusions:

I. There is no sanctity in par; it is merely a convenient round sum to be received in the future.

2. There is no necessary identity between the size of the coupons, or periodical instalments, and the rate of interest.

3. All the recipiends (coupons and par) must be sold below par; their aggregate may amount to more or less than par or to exactly par.

4. The rate of interest= is affected by the degree of beiief in the certainty and punctuality of the payments; and this rate. determins the price.

It may further be stated that no investment is so insecure that, theoretically, it will not be discounted at some rate. A $\$ \mathrm{I}, 000$ bond secured by something which must be annihilated at the end of five years but bearing 30 per cent semi-annual coupons would doubt- 
less find purchasers at better than $\$ 400$ and would be an advantageous purchase.

The market value is of absolutely no importance to an investor who does not contemplate changing the investment but will hold it to maturity. The ups and downs of the market do not in the least affect the value to him; if he were to record these fluctuations it would be merely to substitute an undulating zig-zag for the natural and logical curve of the investment value, since in either case the point of final rest is par at maturity. Such a case is that of a trustee who, under the decisions of the courts of New York, is bound to keep his trust intact, carrying the investments at their investment value and re-investing all in excess.

But to the investor who has the privilege of selling and replacing his investments, acquaintance with market values is highly advantageous. It is his guide to the advisability of making such changes and of forecasting the future. It is his duty therefore to watch the fluctuations of the market and, in a perfectly legitimate way, seek to improve his income, without impairing the factor of safety. A large investor will not endeavor to have all his investments at the same gracie; he will probably have at the same time some capital out at high rates and some at lower. The money at high rates is not quite so secure, not quite so available, and requires more effort for its collection. That at lower rates is nearer to absolute freedom from risk and from labor; it almost automatically collects its own income. On some of the high-interest investments the security may have improved in the course of time; the credit of the municipality or the revenue of the corporation may have so risen that the 4 per cent bond which was bought at par is now selling at a premium which, if a further investment were made, would yield only $3 / 2$ per cent. If the bond has still ten years to run, he may sell at a profit of 4 per cent and thus have \$104 to re-invest in some other 4 per cent security.

Altho the market price is of great utility, I do not admit that it can be introduced into the accountancy of investment. It is not an act nor a fact of the business; it is a statement of what might be done. When the bond just mentioned has gone up to ro4, the owner has not gained a penny. He merely has an opportunity presented; if he lets it pass, the opportunity has not had the slightest effect on his financial status. 
Unless the accounts are kept on the investment-value basis, he cannot even tell whether a certain price would result in a loss or a gain. If his books are kept on the basis of par, every sale above par will appear as a gain, tho it may be a losing bargain; while a comparison with original cost will be equally delusiv.

Where liquidation, entire or partial, is a possible contingency, as in a savings bank or an insurance company, market values are an appropriate basis for an estimate of solvency. It must be remembered, however, that solvency for going on and solvency for winding $u p$ are different matters and that in a going concern, going insolvency is primarily to be considered.

My conclusions as to the proper basis of accountancy for an investor are as follows:

r. Neither original cost nor ultimate par is a proper permanent basis, but the bond should enter at cost, which is a fact, and should go out at par, which is another fact.

2. During the interim the reduction from cost to par should take place gradually by the processes of amortization and accumulation at the basis-rate of true interest.

3. Information should be obtained of the fluctuations in market value, but these should not be carried into the accounts as actualities.

4. A list of market values should accompany the balance sheet of any concern which may be subject to liquidation for the purpose of showing its ability to liquidate.

From the point of view of the banker, the dealer in bonds, which to him are primarily merchandise and only incidentally investment, the conditions of a bond purchase are somewhat different from those outlined above. The banker is entitled to get interest at a fair rate on his current investment, whether the rate secured by his customer is high or low.

This is one of the expenses of his business and the coupons are a help in reducing it. I am of the opinion that the proper method is to treat the bond or lot of bonds as a whole; to debit the account first with the cost, then with interest actually paid to carry it by means of loan capital; to debit also interest on the balance or margin being own-capital, at the rate which could have 
been obtained by loaning it elsewhere. As the coupons mature, their amount is credited and the resulting balance, which is net cost, must be exceeded in the sale to produce any profit. This balance forms the principal of the charge for the next period, and thus the banker receives compound interest.

This procedure, tho apparently different, is precisely analagous to that of the investor. The accretion of interest is charged up and the coupon credited off in both cases. With the investor the rate of interest is predetermined at the time of purchase; with the banker the rate is an actuality, frequently paid in cash, but always referable to a fair standard. 